\title{
Laura Restuccia, Un "Momento" filo-naturalista nella Palermo di fine Ottocento
}

\section{Cecilia Torelli}

\section{(2) OpenEdition}

1 Journals

\section{Edizione digitale}

URL: https://journals.openedition.org/studifrancesi/38186

DOI: 10.4000/studifrancesi.38186

ISSN: 2421-5856

\section{Editore}

Rosenberg \& Sellier

\section{Edizione cartacea}

Data di pubblicazione: 15 décembre 2004

Paginazione: 642

ISSN: 0039-2944

\section{Notizia bibliografica digitale}

Cecilia Torelli, «Laura Restuccia, Un "Momento" filo-naturalista nella Palermo di fine Ottocento», Studi Francesi [Online], 144 (XLVIII | III) | 2004, online dal 30 novembre 2015, consultato il 08 mai 2021. URL: http://journals.openedition.org/studifrancesi/38186; DOI: https://doi.org/10.4000/studifrancesi. 38186

Questo documento è stato generato automaticamente il 8 mai 2021.

\section{(c) $($ ) $\odot$ EY}

Studi Francesi è distribuita con Licenza Creative Commons Attribuzione - Non commerciale - Non opere derivate 4.0 Internazionale. 


\title{
Laura Restuccia, Un "Momento" filo- naturalista nella Palermo di fine Ottocento
}

\author{
Cecilia Torelli
}

\section{NOTIZIA}

LAURA RESTUCCIA, Un “Momento" filo-naturalista nella Palermo di fine Ottocento, AA. VV., Pourquoi la littérature? Esiti italiani del dibattito francese, cit., pp. 31-110.

1 L'A. si sofferma in maniera analitica sulla descrizione della storia e dei contenuti del "Momento letterario", un periodico palermitano, pubblicato per la prima volta nel 1883, che ebbe il merito di entrare nel vivo di quel dibattito culturale europeo che vedeva lo scontro tra l'eredità del Romanticismo e la nascita di nuove tendenze di pensiero, ovvero la teoria positivista in filosofia e quella naturalista in letteratura. Fondato da Giuseppe Pipitone Federico, Girolamo Ragusa Moleti e Pietro Silvestri Marino, in esso scrissero molti intellettuali italiani (tra cui Capuana e Verga), nonché alcuni francesi, François Coppée, Edmond de Gouncourt, Edouard Rod, Hippolyte Taine e Emile Zola. L'importanza di questo periodico risiede nell'aver giocato un ruolo essenziale nella diffusione della letteratura francese contemporanea in Italia: oltre Poictevin, Huysmans, Verlaine, Mallarmé, saranno il naturalismo e soprattutto Zola ad essere al centro dell'indagine critica promossa dal "Momento", indagine che l'A. espone con dovizia di particolari storici e culturali. 